\title{
Effects of Pleasant Ambient Fragrances on Dental Fear: Comparing Apples and Oranges
}

\author{
Alexander Toet • Monique A. M. Smeets • \\ Elly van Dijk • Davina Dijkstra • Lieke van den Reijen
}

Received: 21 May 2010 /Accepted: 2 August 2010 /Published online: 17 August 2010

(C) The Author(s) 2010. This article is published with open access at Springerlink.com

\begin{abstract}
Previous studies showed that orange odor reduces the anticipatory anxiety and improves the mood of patients waiting for scheduled appointments in small dental practices. We replicated these previous studies in the setting of three large dental clinics. In addition, we investigated whether another pleasant fruity smell (apple odor) is similarly associated with reduced anxiety. We included 219 patients (117 males, 102 females) between the ages of 18 and 81 in this study. While they were waiting for dental treatment, the participants were either exposed to the ambient odor of orange $(N=81)$ or apple $(N=69)$, or they received no stimulation. State anxiety, mood, and perceived level of pain of the participants were assessed using questionnaires. Statistical analysis showed no significant difference between the responses of patients in each of the three experimental groups. We therefore conclude that orange and apple odors have no effect on the anticipatory anxiety or mood of patients waiting for scheduled appointments in large dental clinics.
\end{abstract}

Keywords Dental anxiety $\cdot$ Mood $\cdot$ Ambient odor . Orange odor . Apple odor

\footnotetext{
A. Toet $(\square)$

TNO Human Factors,

P.O. Box 23, 3769 ZGSoesterberg, The Netherlands

e-mail: lex.toet@tno.nl

A. Toet $\cdot$ M. A. M. Smeets $\cdot$ E. van Dijk $\cdot$ D. Dijkstra

L. van den Reijen

Department of Clinical and Health Psychology,

Utrecht University,

PO Box 80140,

3508 TCUtrecht, The Netherlands
}

\section{Introduction}

In this study, we investigated whether the presence of orange and apple odors are associated with reduced anxiety in dental patients.

Dental anxiety is a widespread phenomenon throughout the Dutch population, with a high degree of prevalence (Oosterink et al. 2009; Stouthard and Hoogstraten 1990). It is more severe and more strongly associated with intrusive re-experiencing than other phobias (Oosterink et al. 2009). Several instruments have been developed to measure fear of dental treatment (e.g. Newton and Buck 2000; van Wijk and Hoogstraten 2003). Dental anxiety may cause a longterm avoidance of dental treatment (Meng et al. 2010), resulting in a deterioration of oral health state, ultimately leading to pain and distress (Hmud and Walsh 2007), and negative effects on social life (Berggren 1993). The resulting prospect of potentially invasive treatments may reinforce existing avoidance behavior, thus instigating a vicious cycle of avoidance behavior, anticipatory anxiety, and suffering (Armfield et al. 2007). In addition, dentists identify treating nervous patients as a major source of stress (Hill et al. 2008; Moore and Brødsgaard 2003), which may compromise their performance. Managing dental anxiety is therefore recognized as an important issue in dental practice (Bare and Dundes 2004; Pawlicki 1991).

Helping patients overcome their apprehensions can reduce the incidence of delayed or missed dental visits and the negative repercussions from avoidance of needed care, can decrease their perception of pain (Loggia et al. 2008), and may ultimately improve their quality of life (Berggren 1993; Cohen et al. 2000; Locker 2003; Vermaire et al. 2007). In addition, allaying dental anxiety may also reduce perceived pain unpleasantness (Villemure et al. 2003), thus facilitating the work of dentists. Even the 
implementation of a single strategy that calms a small proportion of tense patients may therefore yield benefits for patients and practitioners alike. Dental anxiety management techniques currently include pharmacological interventions (Leitch and Macpherson 2007), behavioral and distraction techniques (Pawlicki 1991), or a combination of both (Dworkin 1986; Hmud and Walsh 2007). Pharmacological interventions like sedative drugs, anesthesia, sedation or local analgesia, inherently carry some risk (Haas 2002), and require special knowledge and equipment. Behavioral and distraction methods are time consuming and require additional professional expertise (Hmud and Walsh 2007; Pawlicki 1991). As a result, behavioral anxiety management techniques are not widely used due to a lack of time and funds (Hill et al. 2008), resulting in an overutilization of pharmacologic agents (Pawlicki 1991). New unobtrusive and inexpensive anxiety management methods would therefore be of great practical value to the dental profession.

Next to fear of pain, cognitive perceptions and past traumatic dental experiences (Armfield 2010), the sights (needles, air turbine drills), sounds (drilling, screaming), smells (eugenol, cut dentine), and sensations (high frequency vibrations) in the dental setting are a major cause of dental anxiety (Berggren and Meynert 1984; Hmud and Walsh 2007; Oosterink et al. 2008; Walsh 2007). Removing or masking these four major sensory triggers for dental anxiety may mitigate anxiety (Hmud and Walsh 2007; Walsh 2007).

Patients commonly experience the period of time spent waiting for dental treatment as particularly anxiety provoking, since it provides them time to think about what will (or could) happen, and to ruminate on worst-case outcomes (Cohen et al. 2000). In this situation, the characteristic smell of eugenol, which typically clings to dental offices, may contribute to their apprehension by eliciting memories of previous unpleasant dental care experiences, involving painful restorative dentistry on vital teeth (Robin et al. 1998; Robin et al. 1999; Robin et al. 2000). Introducing pleasant ambient odors in the dental environment may help to reduce dental anxiety in two ways: by masking the smell of eugenol and by the potential anxiolytic effects of the odors themselves. It has indeed been observed that pleasant scents like orange and lavender appear to reduce patient anxiety levels (Kritsidima et al. 2010; Lehrner et al. 2000; Lehrner et al. 2005).

Evidence for the anxiolytic effects of inhalation of pleasant scents like essential oils is provided by studies on both animals (Bradley et al. 2007; Chen et al. 2008; de Almeida et al. 2004; Faturi et al. 2010; Komiya et al. 2006; Leite et al. 2008) and man (McCaffrey et al. 2009; Motomura et al. 2001; Peng et al. 2009; Robin et al. 1998; Saeki and Shiohara 2001). In healthy humans, inhalation of lavender significantly reduces the levels of salivary cortisol (Atsumi and Tonosaki 2007), salivary chromogranin (Toda and Morimoto 2010), and serum cortisol (Shiina et al. 2008), increases blood flow, and decreases galvanic skin conductance and systolic blood pressure (Saeki and Shiohara 2001). The odors of jasmine tea and lavender significantly decrease heart rate, and induce calm and vigorous mood states (Kuroda et al. 2005). In clinical settings, the inhalation of pleasant fragrances has effectively been deployed to reduce anxiety in surgical patients (Braden et al. 2009), in hemodialysis patients (Itai et al. 2000), and in patients during MR imaging (Redd et al. 2009), but failed to reduce anxiety in cancer patients (Graham et al. 2003; Louis and Kowalski 2002) and patients awaiting endoscopy (Muzzarelli et al. 2006). This suggests that aromatherapy may be more effective at moderate levels of anxiety than at extreme levels of anxiety (Muzzarelli et al. 2006).

Two potential mechanisms for the effects of odors on mood, behavior, and physiology have been proposed: pharmacological and psychological (Herz 2009). Following the pharmacological mechanism, odors exert direct effects on the central/autonomic nervous system and endocrine system independent of conscious evaluation. Following the psychological hypothesis, effects depend on emotional learning, conscious perception, and beliefs and expectations (Herz 2009). Based on her review of 18 studies, Herz (2009) concluded in favor of the psychological hypothesis, stating that perceived quality of the odor was the most relevant factor accounting for individual responses to odors. Therefore, in the present study, which aimed to replicate the Lehrner et al. (2000, 2005) studies showing reduced patient anxiety in dentists' waiting rooms when exposed to the odor of orange essential oil, we adopted the psychological hypothesis, which holds that odors exert effects as a result of previous associations with pleasant events (such as eating a tasty fruit). In addition to a no odor control condition, we included an apple odor condition based on the finding that both odors are among the most pleasant (Dalton et al. 2008). The scents of apples and oranges are quite familiar to the Dutch population and are typically associated with fresh fruit. Cross-cultural studies (Zarzo 2008) have indeed shown that scents which are classified as fruity and edible are generally also perceived as pleasant. If effects are based on pleasantness, we would expect apple odor to be equally effective as orange odor.

\section{Methods}

\section{Participants}

A total of 242 patients filled out the questionnaires. We excluded 23 patients, either because they did not complete the questionnaire, because they showed an obvious answer- 
ing tendency, such as using extreme scores on all items, or because they were insufficiently fluent in the Dutch language, which became apparent during instructions or completion of the questionnaire. We included the remaining 219 patients (117 males, 102 females) between the ages of 18 and 81 in this study. Table 1 lists the distribution of sex and age of the participants over the three experimental conditions. The experimental protocol was approved by the TNO Human Factors internal review board on experiments with human participants, and was performed in accordance with the Helsinki Declaration of 1975, as revised in 2000 (World Medical Association 2000).

\section{Environmental Conditions}

The study was performed in the waiting rooms of three large dental clinics in the Rotterdam area in the Netherlands, participating in the dental cooperation 'Samenwerkende Tandartsen Rotterdam'. Each of these clinics handles between 70 and 80 patients per day, and employs several dentists. The three waiting rooms varied in size from about $10-100 \mathrm{~m}^{2}$. They were all well lit (between 100 and 600 lx, thus ranging from standard corridor lighting to normal office lighting levels), with light-colored walls, and provided sufficient distraction for the patients (magazines, posters and artwork on the walls, toys, coffee machines, etc.). Sounds coming from the surgery were clearly perceptible in two of the waiting rooms, and were only just noticeable in the third one. One clinic was situated above an orthodontic lab which dispersed a strong scent of mono-methylmethacrylate. In another clinic, the scent of eugenol was clearly noticeable. The third clinic did not have a typical scent of its own. Waiting rooms were assigned to all odor conditions in a withinlocation design over three subsequent weeks. Measurements were collected during 1 day per week for each waiting room. The order of odor presentation was counterbalanced over conditions. So in total, there were three measurement sessions per clinic.

\section{Apparatus and Stimuli}

The odors used in this study were Orange Oil Florida Valencia Coldpressed (1900-226, C-8289) and Apple Green 5914 (Sensient Essential Oils Germany GmbH, Bremen: www.essentialoils.de). The main component of the orange oil was determined by chromatography-mass spectrometry to be limonene. The limonene/myrcene ratio was about $100 / 4$, which is similar to the ratio used in previous studies (Lehrner et al. 2000; Lehrner et al. 2005). In the odor conditions, the oils were diffused in the waiting rooms by electric Xenon XLS dispensers with electronic timing devices (Sense Company, www.sense-company.nl). No odor was applied in the control condition. In each of the three clinics, two dispensers were placed in the waiting room, hidden from the patients view. Each dispenser could cover an area of about $50 \mathrm{~m}^{2}$ and was positioned so as to be invisible to the patients.

\section{Measurements}

Anxiety levels were assessed using the 'Zelf-Beoordelings Vragenlijst' (ZBV), a Dutch version of the Spielberger StateTrait Anxiety Inventory (STAI-form version Y; van der Ploeg 1984; van der Ploeg 2000; see also Newton and Buck 2000). The state anxiety part of the ZBV was administered, consisting of 20 questions addressing the current emotional state of the participants, which can be answered on a fourpoint Likert scale ('not at all', 'slightly', 'moderately', 'extremely'). High ZBV scores mean more state anxiety and low scores mean less.

Subsequently, the mood, alertness, and calmness of the participants while waiting for the dental procedure, and during the days just prior to the visit to the dental clinic, were assessed using an abbreviated version of the Dutch translation of the Profile of Mood States (POMS: Wald and Mellenbergh 1990). This questionnaire consists of 32 questions addressing five different moods: depression, anger, fatigue, vigor, and tension. All these questions can be answered on a five point Likert scale ('not at all', 'slightly', 'somewhat', 'moderately', and 'extremely'). Higher POMS sum scores correspond to higher levels of psychological distress.

The participants were also asked to indicate their current experienced pain level on a seven-point Likert scale ranging from 1 ('no pain at all') to 7 ('extreme pain').

Additional demographic variables that were collected included age, gender, education, proficiency in the Dutch language, and the nature of the anticipated dental procedures.

Next, to assess a potential awareness of the presence of an ambient odor, the participants were requested to compare the waiting room on a three-point rating scale relative to other
Table 1 Distribution of sex and age of the participants over the three odor conditions

\begin{tabular}{|c|c|c|c|c|c|c|c|c|c|}
\hline & \multicolumn{3}{|c|}{ Orange } & \multicolumn{3}{|c|}{ Apple } & \multicolumn{3}{|c|}{ No odor } \\
\hline & $N$ & M (age) & SD & $N$ & M (age) & $\mathrm{SD}$ & $N$ & M (age) & $\mathrm{SD}$ \\
\hline Males & 44 & 43.73 & 15.60 & 38 & 37.26 & 12.76 & 35 & 45.80 & 16.93 \\
\hline Females & 37 & 40.30 & 14.87 & 31 & 37.00 & 13.43 & 34 & 43.47 & 16.24 \\
\hline Total & 81 & 42.16 & 15.27 & 69 & 37.14 & 12.97 & 69 & 44.65 & 16.51 \\
\hline
\end{tabular}


waiting rooms they had experienced, on the dimensions of size ('larger', 'smaller', 'similar'), lightness ('brighter', 'darker', 'similar'), smell ('more pleasant', 'less pleasant', 'similar'), and the presence of reading material ('more magazines', 'less magazines', 'similar'). The smell-related question served to assess whether the participants were aware of the presence of a scent in the waiting room. This question was unobtrusively embedded among the other questions in order not to explicitly draw their attention to the presence of an odor.

Finally, participants had the opportunity to enter remarks and spontaneous observations.

Answering the questionnaires was entirely self-paced, and typically took about $5-10 \mathrm{~min}$.

\section{Procedure}

In the odor conditions, the dispensers were activated about half an hour before the arrival of the first patients. Their timers were set such that the oils were nebulised for $10 \mathrm{~s}$ every $2 \mathrm{~min}$. In the control condition, water was nebulised instead of aromatic oil.

Pilot studies were performed prior to the actual experiments in order to adjust the odor concentration to the desired level. This was done by letting ten patients fill out a brief questionnaire while waiting for treatment. Patients were first asked whether they noticed anything particular about the waiting room. Then they were informed that a scent had been dispersed, and they were asked whether they could discern it, and if so, to rate the strength and pleasantness of the smell on a nine-point Likert scale. Finally, they were asked to identify the smell. The actual experiment started when the mean (over ten patients) perceived odor strength was within the target level range of 4.5-5. If the mean odor strength was outside the target range (implying that the scent was either too weak or too strong) the experimenters adjusted the dispenser setting, and again interviewed ten different patients. This procedure was repeated until the perceived odor strength was within the target range. The target level was set so the odor could be perceived and its quality and pleasantness determined. For both odors used in this study, the mean perceived intensity was 4.7 , and the mean perceived pleasantness was 5.The reason not to use very high concentrations was based on the fact that odors which are appraised as pleasant in lower concentrations may be judged as unpleasant in higher doses (Henion 1971).

Patients over 18 years of age who arrived at the dental practices, and who indicated to be both actively and passively proficient in the Dutch language were invited to participate in the main study while waiting for treatment. After briefly introducing themselves, the experimenters informed the patients that they were performing a study about dental anxiety. When the patients consented to participate in the study, the experimenters handed them the questionnaires. After the participants had completed the various questionnaires in the same order as specified under "measurements", the experimenters thanked them for their participation.

Changing the oil cartridges in the odor delivery systems was done according to standard procedures as described in the manual provided by the manufacturer.

\section{Statistical Analysis}

Since the STAI sum scores, the POMS sum scores, and level of pain were correlated (see Table 4), a multivariate analysis of variance (ANOVA) was conducted using location and odor treatment groups as fixed factors, followed by post-hoc Tukey tests when the overall effect was statistically significant (Field 2009). As significant differences in age between odor conditions were encountered, age was entered as a covariate. Chi-square tests were used to assess differences between the conditions for locations and gender, education, fluency in the Dutch language, and the nature of the dental procedures. For all analyses, a probability level of $p<0.05$ was considered to be statistically significant. All statistical analyses were performed with SPSS 16.0 for Windows (SPSS, Chicago, IL, USA).

\section{Results}

\section{Sample Set Characteristics}

A one-way ANOVA revealed a significant age difference between the different odor conditions $(F(2,216)=4.498, p<$ 0.05). Post-hoc Tukey HSD tests showed that the mean age of the participants in the apple odor condition was significantly lower than the mean age in the no-odor condition. ( $p=0.010$, see Table 2). The mean age in the orange condition was not significantly different from the mean ages in the other two conditions.

A chi-square test showed no significant difference in the proportion of males to females between the three odor conditions $\left(\chi^{2}(2, N=218)=0.304, p>0.05\right)$.

Education was clustered into two groups. The first group contained 'no education', 'primary education', and 'secondary education'. The second group consisted of 'vocational education' and 'university education'. A chi-square test showed no significant difference in the proportion of the two educational groups between the three odor conditions $\left(\chi^{2}(2, N=219)=0.052, p>0.05\right)$.

Table 3 lists the anticipated dental treatments for each of the three odor conditions. The 'other' option included treatments like extraction, placing a dental crown or dental splint, etc. There was no significant difference in the 
Table 2 Sample set characteristics for the three odor conditions

\begin{tabular}{llll}
\hline & Orange odor & Apple odor & No odor \\
\hline$N$ & 81 & 69 & 69 \\
M (SD) age & $42.16(15.27)$ & $37.14(12.97)$ & $44.65(16.51)$ \\
Age range & $18-80$ & $18-64$ & $18-81$ \\
\% Females & 45.7 & 49.3 & 44.9 \\
Education & Higher vocational & Upper secondary & Upper secondary \\
& education & vocational education & vocational education \\
\hline
\end{tabular}

proportion of the anticipated dental treatments between the three odor conditions $(\chi 2(10, N=219)=9.96, p>0.4)$. It was noted that five out of 18 cells contain less than five observations.

\section{Research Questions}

A multivariate analysis of variance (MANOVA) was conducted on location (three levels) and odor treatment condition (three levels), with age as covariate. The use of MANOVA was deemed appropriate because of the significant correlations between the STAI sum scores, the POMS sum scores, and the level of pain experienced (see Table 4). The covariate age was significant $(F(3,202)=3.38, p=0.02)$. Multivariate tests for location, odor condition, and location $\times$ odor condition were all non-significant, with all $F<1.0$. Corresponding partial $\eta^{2}$ all indicated low effect sizes; $\eta^{2}=$ $0.010, \eta^{2}=0.008$, and $\eta^{2}=0.019$ for location, odor condition, and location $\times$ odor condition, respectively. Because of lack of significance at the multivariate level, no univariate tests or Tukey post hocs are reported. There were no meaningful differences in results (i.e., results all indicated nonsignificance) between the MANOVA including age as covariate reported above and a MANOVA not including the covariate.

Anticipated dental treatment is likely to be associated with different levels of anxiety. Effectiveness of exposure to the odor of essential oils on anxiety, mood, and pain may vary depending on anticipated treatment. To investigate possible interactions between anticipated treatment and odor condition, we conducted a MANOVA on anxiety, mood, and pain, with treatment (we only included the three

Table 3 Anticipated dental treatments for the three odor conditions

\begin{tabular}{llll}
\hline & Orange odor & Apple odor & No odor \\
\hline Check-up & 35 & 33 & 37 \\
Drilling & 14 & 14 & 13 \\
Root canal treatment & 15 & 13 & 10 \\
Dental prosthesis & 6 & 2 & 2 \\
Dental hygiene & 1 & 4 & 1 \\
Other & 10 & 3 & 6 \\
\hline
\end{tabular}

treatments "check-up", "drilling", and "root canal", which categories had more than five observations per cell) and odor condition as fixed factors. Again, the covariate age was significant: $F(3,167)=2.73, p=0.046$. There was an effect of anticipated treatment $F(6,335)=8.13, p<0.001$. The results show a pattern in which root canal treatment is associated with significantly higher levels of pain than check up and drilling (Bonferrroni corrected), significantly higher anxiety compared to check-up (Bonferroni corrected), but not with significant differences in mood. However, there was no interaction of treatment $\times$ odor condition: $F<1.0$. Thus, odor did not differentially affect anxiety, mood, or pain depending on anticipated treatment.

\section{Gender Effects}

Tables 5 and 6 show the mean scores of male and female dental patients on the STAI and the POMS questionnaires, respectively. For both male and female dental patients, the STAI scores were higher than the scores for a random sample of respectively male $(M=36.4, S D=10.3)$ and female $(M=$ 38.8, $S D=13.2$ ) citizens of Leiden (The Netherlands), which are considered as the norm scores (van der Ploeg 2000). This implies that the dental patients who participated in this study had a higher state anxiety than the norm groups, as expected.

A $3 \times 3 \times 2$ MANOVA was performed with location, odor condition, and gender as fixed factors, and the sum scores on the STAI and the POMS questionnaires and the 'experienced pain level' as dependent variables. Again, age was entered as covariate $(F(3,193)=3.86, p=0.01)$. Effects of location $(F<1.0)$, odor condition $(F<1.0)$, and location $\times$ condition $(F<1.0)$ were all nonsignificant. The only significant effect was that of gender: $(F(3,193)=3.34$,

Table 4 Pearson's correlations between the STAI sum scores, the POMS sum scores and the level of pain experienced

\begin{tabular}{lll}
\hline Correlation & $\begin{array}{l}\text { Pain level } \\
(N=214)\end{array}$ & $\begin{array}{l}\text { POMS sum } \\
\text { score }(N=219)\end{array}$ \\
\hline STAI sum score & 0.273 & 0.555 \\
POMS sum score & 0.379 & \\
\hline
\end{tabular}

All correlations are significant at the $p<0.01$ level (two-tailed) 
Table 5 Mean STAI scores of males and females in the three odor conditions

\begin{tabular}{|c|c|c|c|c|c|c|c|c|}
\hline & \multicolumn{2}{|c|}{ Orange odor } & \multicolumn{2}{|c|}{ Apple odor } & \multicolumn{2}{|c|}{ No odor } & \multicolumn{2}{|c|}{ Norm } \\
\hline & M & SD & $\mathrm{M}$ & SD & $\mathrm{M}$ & SD & $\mathrm{M}$ & SD \\
\hline Males & 39.66 & 11.27 & 39.89 & 10.82 & 37.17 & 9.85 & 36.4 & 10.3 \\
\hline Females & 40.95 & 11.03 & 39.61 & 13.20 & 39.56 & 11.00 & 38.8 & 13.2 \\
\hline Total & 40.25 & 11.12 & 39.77 & 11.86 & 38.35 & 10.42 & & \\
\hline
\end{tabular}

$p=0.02$ ). Partial $\eta^{2}$ for gender was 0.049 , all other partial $\eta^{2}$ were $\leq 0.02$, implying low effect sizes. Female patients scored significantly lower on the POMS $(F(1,216)=5.84$, $p=0.02$ ), implying that they were in a more positive mood than male patients, but there was no odor effect on the scores. Exclusion of the covariate age did not affect the results, resulting in the same pattern of significant and nonsignificant effects.

Figure 1 shows that the POMS scores in the orange condition were higher than the POMS scores in the no-odor condition, both for men and women. However, this difference is not significant. There was also no gender effect on the experienced level of pain $(F(1,208)=2.77, p>0.05)$, and no odor interaction effect $(F<1.0)$.

\section{Odor Evaluations}

Patients were not explicitly asked to rate the odor present in the waiting room. They compared the waiting room they were in with other waiting rooms they had experienced on a number of characteristics, one of which was odor. Table 7 shows that the majority of patients did not rate the odor in the room to be different from other waiting rooms, with no effect of condition $\left(\chi^{2}(4, N=219)=2.98, p>0.05\right)$. This suggests that the odor was not consciously noted.

\section{Discussion}

Previous studies reported an anxiolytic effect of orange odor on patient anxiety in the setting of small dental clinics (Lehrner et al. 2000; Lehrner et al. 2005). The relaxing

Table 6 Mean POMS scores of males and females in the three odor conditions

\begin{tabular}{|c|c|c|c|c|c|c|}
\hline & \multicolumn{2}{|c|}{ Orange odor } & \multicolumn{2}{|c|}{ Apple odor } & \multicolumn{2}{|c|}{ No odor } \\
\hline & M & SD & M & $\mathrm{SD}$ & M & SD \\
\hline Males & 56.16 & 18.99 & 52.92 & 13.95 & 52.71 & 12.87 \\
\hline Females & 50.43 & 12.75 & 52.42 & 16.98 & 46.53 & 9.82 \\
\hline Total & 53.54 & 16.59 & 52.70 & 15.27 & 49.67 & 11.81 \\
\hline
\end{tabular}

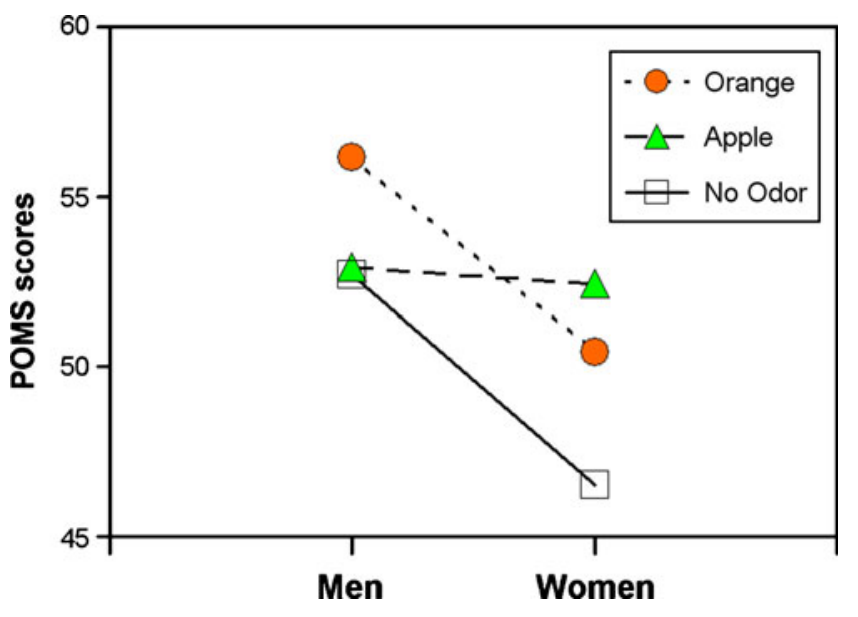

Fig. 1 Mean POMS scores for men and women

properties of the inhalation of orange oil were also established in physiological studies on humans (Peng et al. 2009), and in animal studies (Faturi et al. 2010; Leite et al. 2008). However, the results of the present study show that neither orange nor apple odors were associated with lower anticipatory anxiety in patients waiting for scheduled appointments in large dental clinics. Not only were the effects associated with the odor manipulations of orange and apple not significant, they (in terms of $\eta^{2}$ ) were also very small in size. The odor of apple was included to match for pleasantness. However, neither of the pleasant fruity odors showed any effects on anxiety, mood, or pain.

Although citrus odors have a stress-alleviating effect (Komiya et al. 2006), which is probably due to their limonene components (Carvalho-Freitas and Costa 2002; Fukumoto et al. 2008; Komiya et al. 2006; Peng et al. 2009), they also have stimulating properties, which increase vigilance and arousal (Baron and Kalsher 1998; Martin and Cooper 2007; Warrenburg 2005). The resulting increased sensory awareness may make people more alert to their pain. It has indeed been shown that people who are exposed to a pleasant lemon scent experience more pain (Martin 2006). These contrasting effects may have acted to cancel each other out. It is further possible that the effects of orange essential oil interact with internal (i.e., level of pain) and external (room) characteristics in a more complex manner than previously assumed.

Table 7 The ambient odor in the waiting room rated relative to previously experienced waiting rooms

\begin{tabular}{lccr}
\hline & Orange odor (\%) & Apple odor (\%) & No odor (\%) \\
\hline Smells better & $9(11.1)$ & $9(13.0)$ & $8(11.6)$ \\
Smells worse & $11(13.6)$ & $9(13.0)$ & $4(5.8)$ \\
$\begin{array}{l}\text { No difference } \\
\text { in smell }\end{array}$ & $61(75.3)$ & $51(73.9)$ & $57(82.6)$ \\
\hline
\end{tabular}


The protocol used in the present study was similar to the ones used in previous studies (Kritsidima et al. 2010; Lehrner et al. 2000; Lehrner et al. 2005). However, the present study was performed in the waiting rooms of large dental clinics, whereas previous studies concerned small dental practices (Kritsidima et al. 2010; Lehrner et al. 2000; Lehrner et al. 2005). In large practices, there is a continuous coming and going of patients, and more background activity due to a larger dental staff. In the present study, this may have provided the waiting dental patients an additional source of distraction, thereby lowering their self-awareness and reducing their anxiety.

Summarizing, we conclude that orange and apple odors have no effect on anticipatory anxiety in patients waiting for scheduled appointments in large dental clinics. However, further investigations should resolve whether these scents may ultimately reduce the anxiety of patients with higher levels of pain by stimulating their sensory awareness.

Acknowledgments This research was supported by MAGW VIDI grant 452-03-334 of the Netherlands Organization for Scientific Research (N.W.O.) to M.A.M.S. We thank the 'Samenwerkende Tandartsen Rotterdam' (STR) in general, and the employees of the dental practices 'De Groot', 'Tand-Art' and 'Mathenesse' in particular, for their enthusiastic and spontaneous assistance with this research and their generous hospitality. We are particularly indebted to dr. H.R. Schneider, both for his role as liaison with 'Samenwerkende Tandartsen Rotterdam', and for establishing the contacts with the dental practices that participated in this study. We appreciate the help of Jeroen van der Meer and Daan Noort (TNO Business Unit CBRN Protection) with the chemical analysis of the orange oil. We also thank Ewoud Kuyper (Sense Company, Tilburg, The Netherlands) for his help with the installation of the scent dispensers.

Open Access This article is distributed under the terms of the Creative Commons Attribution Noncommercial License which permits any noncommercial use, distribution, and reproduction in any medium, provided the original author(s) and source are credited.

\section{References}

Armfield JA (2010) Towards a better understanding of dental anxiety and fear: cognitions vs. experiences. Eur J Oral Sci 118:259-264

Armfield JA, Stewart JF, Spencer AJ (2007) The vicious cycle of dental fear: exploring the interplay between oral health, service utilization and dental fear. BMC Oral Health 7 doi:10.1186/1472-6831-7-1

Atsumi T, Tonosaki K (2007) Smelling lavender and rosemary increases free radical scavenging activity and decreases cortisol level in saliva. Psychiatry Res 150:89-96

Bare LC, Dundes L (2004) Strategies for combating dental anxiety. J Dent Educ 68:1172-1177

Baron RA, Kalsher MJ (1998) Effects of a pleasant ambient fragrance on simulated driving performance. Environ Behav 30:535-552

Berggren U (1993) Psychosocial effects associated with dental fear in adult dental patients with avoidance behaviours. Psychol Health 8:185-196

Berggren U, Meynert G (1984) Dental fear and avoidance: causes, symptoms, and consequences. J Am Dent Assoc 109:247-251
Braden R, Reichow S, Halm MA (2009) The use of the essential oil lavandin to reduce preoperative anxiety in surgical patients. J Perianesth Nurs 24:348-355

Bradley BF, Starkey NJ, Brown SL, Lea RW (2007) Anxiolytic effects of Lavandula angustifolia odour on the Mongolian gerbil elevated plus maze. J Ethnopharmacol 111:517-525

Carvalho-Freitas MIR, Costa M (2002) Anxiolytic and sedative effects of extracts and essential oil from Citrus aurantium L. Biol Pharm Bull 25:1629-1633

Chen Y-J, Shih Y, Chang T-M, Wang M-F, Lan S-S, Cheng F-C (2008) Inhalation of neroli essential oil and its anxiolytic effects in animals. In: Spink AJ et al (eds) Proceedings of measuring behavior 2008. Maastricht, The Netherlands, pp 256-257

Cohen SM, Fiske J, Newton JT (2000) The impact of dental anxiety on daily living. Br Dent J 189:385-390

Dalton P, Maute C, Oshida A, Hikichi S, Izumi Y (2008) The use of semantic differential scaling to define the multi-dimensional representation of odors. J Sens Stud 23:485-497

de Almeida RN, Motta SC, de Brito FC, Catallani B, Leite JR (2004) Anxiolytic like effects of rose oil inhalation on the elevated plus maze test in rats. Pharmacol Biochem Behav 77:361-364

Dworkin SF (1986) Integrating behavioral and pharmacological therapeutic modalities. Anesth Prog 33:29-33

Faturi CB, Leite JR, Alves PB, Canton AC, Teixeira-Silva F (2010) Anxiolytic-like effect of sweet orange aroma in Wistar rats. Progr Neuro Psychopharmacol Biol Psychiatr 34(4):605-609

Field A (2009) Discovering statistics using SPSS, 3rd edn. Sage, Thousand Oaks

Fukumoto S, Morishita A, Furutachi K, Terashima T, Nakayama T, Yokogoshi H (2008) Effect of flavour components in lemon essential oil on physical or psychological stress. Stress Health 24:3-12

Graham PH, Browne L, Cox H, Graham J (2003) Inhalation aromatherapy during radiotherapy: results of a placebo-controlled doubleblind randomized trial. J Clin Oncol 21:2372-2376

Haas DA (2002) An update on local anesthetics in dentistry. J Can Dent Assoc 68:546-551

Henion KE (1971) Odor pleasantness and intensity: a single dimension? J Exp Psychol 90:275-279

Herz RS (2009) Aromatherapy facts and fictions: a scientific analysis of olfactory effects on mood, physiology and behavior. Int $\mathrm{J}$ Neurosci 119:263-290

Hill KB, Hainsworth JM, Burke FJ, Fairbrother KJ (2008) Evaluation of dentists' perceived needs regarding treatment of the anxious patient. Br Dent J 204:1-5

Hmud R, Walsh LJ (2007) Dental anxiety: causes, complications and management approaches. J Minim Interv Dent 2:67-78

Itai T et al (2000) Psychological effects of aromatherapy on chronic hemodialysis patients. Psychiatry Clin Neurosci 54:393-397

Komiya M, Takashi T, Harada E (2006) Lemon oil vapor causes an anti-stress effect via modulating the 5-HT and DA activities in mice. Behav Brain Res 172:240-249

Kritsidima M, Newton T, Asimakopoulou K (2010) The effects of lavender scent on dental patient anxiety levels: a cluster randomised-controlled trial. Community Dent Oral Epidemiol 38:83-87

Kuroda K, Inoue N, Ito Y, Kubota K, Sugimoto A, Kakuda T, Fushiki T (2005) Sedative effects of the jasmine tea odor and $(R)-(-)$-linalool, one of its major odor components, on autonomic nerve activity and mood states. Eur J Appl Physiol 95:107-114

Lehrner J, Eckersberger C, Walla P, Pötsch G, Deecke L (2000) Ambient odor of orange in a dental office reduces anxiety and improves mood in female patients. Physiol Behav 71:83-85

Lehrner J, Marwinski G, Lehr S, Johren P, Deecke L (2005) Ambient odors of orange and lavender reduce anxiety and improve mood in a dental office. Physiol Behav 86:92-95 
Leitch J, Macpherson A (2007) Current state of sedation/analgesia care in dentistry. Curr Opin Anaesthesiol 20:384-387

Leite MP, Fassin J, Baziloni EMF, Almeida RN, Mattei R, Leite JR (2008) Behavioral effects of essential oil of Citrus aurantium L. inhalation in rats. Revista Brasileira de Farmacognosia 18:661-666

Locker D (2003) Psychosocial consequences of dental fear and anxiety. Community Dent Oral Epidemiol 31:144-151

Loggia ML, Schweinhardt P, Villemure C, Bushnell MC (2008) Effects of psychological state on pain perception in the dental environment. J Can Dent Assoc 74:651-656

Louis M, Kowalski SD (2002) Use of aromatherapy with hospice patients to decrease pain, anxiety, and depression and to promote an increased sense of well-being. Am J Hosp Palliat Med 19:381-386

Martin GN (2006) The effect of exposure to odor on the perception of pain. Psychosom Med 68:613-616

Martin GN, Cooper JA (2007) Adding zest to difficult journeys: odour effects on simulated driving performance. Poster presented at the British Psychology Society Annual Conference. York, UK, pp

McCaffrey R, Thomas DJ, Kinelman AO (2009) The effects of lavender and rosemary essential oils on test-taking anxiety among graduate nursing students. Holist Nurs Pract 23:88-93

Meng X, Heft MW, Bradley MM, Lang PJ (2010) Effect of fear on dental utilization behaviors and oral health outcome. Community Dent Oral Epidemiol 35:292-301

Moore R, Brødsgaard I (2003) Dentists' perceived stress and its relation to perceptions about anxious patients. Community Dent Oral Epidemiol 29:73-80

Motomura N, Sakurai A, Yotsuya Y (2001) Reduction of mental stress with lavender odorant. Percept Mot Skills 93:713-718

Muzzarelli L, Force M, Sebold M (2006) Aromatherapy and reducing preprocedural anxiety: a controlled prospective study. Gastroenterol Nurs 29:466-471

Newton JT, Buck DJ (2000) Anxiety and pain measures in dentistry: a guide to their quality and application. J Am Dent Assoc 131:1449-1457

Oosterink FMD, de Jongh A, Aartman IHA (2008) What are people afraid of during dental treatment? Anxiety-provoking capacity of 67 stimuli characteristic of the dental setting. Eur J Oral Sci 116:44-51

Oosterink FMD, de Jongh A, Hoogstraten J (2009) Prevalence of dental fear and phobia relative to other fear and phobia subtypes. Eur J Oral Sci 117:135-143

Pawlicki RE (1991) Psychological/behavioral techniques in managing pain and anxiety in the dental patient. Anesth Prog 38:120-127

Peng S-M, Koo M, Yu Z-R (2009) Effects of music and essential oil inhalation on cardiac autonomic balance in healthy individuals. J Altern Complement Med 15:53-57
Redd WH, Manne SL, Peters B, Jacobsen PB, Schmidt H (2009) Fragrance administration to reduce anxiety during MR imaging. J Magn Reson Imaging 4:623-626

Robin O, Alaoui-Ismaïli O, Dittmar A, Vernet-Maury E (1998) Emotional responses evoked by dental odors: an evaluation from autonomic parameters. J Dent Res 77:1638-1646

Robin O, Alaoui-Ismaïli O, Dittmar A, Vernet-Maury E (1999) Basic emotions evoked by eugenol odor differ according to the dental experience. A neurovegetative analysis. Chem Sens 24:327-335

Robin O, Alaoui-Ismaïli O, Dittmar A, Vernet-Maury E (2000) Emotional responses induced by dental odors. The Aroma-Chology Review IX:2-3.

Saeki Y, Shiohara M (2001) Physiological effects of inhaling fragnances. Int J Aromather 11:118-125

Shiina Y et al (2008) Relaxation effects of lavender aromatherapy improve coronary flow velocity reserve in healthy men evaluated by transthoracic Doppler echocardiography. Int J Cardiol 129:193-197

Stouthard MEA, Hoogstraten J (1990) Prevalence of dental anxiety in The Netherlands. Community Dent Oral Epidemiol 18:139-142

Toda M, Morimoto K (2010) Effect of lavender aroma on salivary endocrinological stress markers. Arch Oral Biol 53:964-968

van der Ploeg HM (2000) Handleiding bij de Zelfbeoordelingsvragenlijst: een Nederlandse bewerking van de Spielberger State Trait Anxiety Inventory [Manual to the Dutch version of the Spielberger State Trait Anxiety Inventory]. Swets Test Publishers, Lisse

van der Ploeg HM (1984) The development and validation of the Dutch form of the Test Anxiety Inventory. Appl Psychol 33:243-254

van Wijk AJ, Hoogstraten J (2003) The fear of dental pain questionnaire: construction and validity. Eur J Oral Sci 111:12-18

Vermaire JH, de Jongh A, Aartman IHA (2007) Dental anxiety and quality of life: the effect of dental treatment. Community Dent Oral Epidemiol 36:409-416

Villemure C, Slotnick BM, Bushnell MC (2003) Effects of odors on pain perception: deciphering the roles of emotion and attention. Pain 106:101-108

Wald FDM, Mellenbergh GJ (1990) Instrumenteel onderzoek: de verkorte versie van de Nederlandse vertaling van de Profile of Mood States (POMS). Nederlandsch Tijdschrift voor de Psychologie 45:86-90

Walsh LJ (2007) Anxiety prevention: implementing the $4 \mathrm{~S}$ principle in conservative dentistry. Auxiliary 17:24-26

Warrenburg S (2005) Effects of fragrance on emotions: moods and physiology. Chem Sens 30:i248-i249

World Medical Association (2000) World Medical Association Declaration of Helsinki: ethical principles for medical research involving human subjects. J Am Med Assoc 284:3043-3045

Zarzo M (2008) Psychologic dimensions in the perception of everyday odors: pleasantness and edibility. J Sens Stud 23:354-376 